\title{
CORESPONDENȚE SIMBOLICE ÎNTRE ARTA ICONOGRAFICĂ, PICTURĂ ȘI ARTĂ MONUMENTALĂ ÎN CREAȚIA ARTISTIICĂ PERSONALĂ
}

\author{
Nicolae SUCIU* \\ Symbolic correspondence between the iconographic art, painting and \\ monumental art in the personal artistic creation
}

\begin{abstract}
The fascination and mystery of Easter represented in my own pictorial creation - "Veil of Saint Veronica", "Crucifixions by the roadside", "Resurrection Night". My childhood universe was marked by religious instruction received in the family from my mother, starting with the evening prayer, reading from the calendar each morning, the religious celebrations and its significance. The icon in the house and ,iconostasis" and the paintings from the village church, make up the dowry and spiritual charge of my artistic profile that I came back to every time, in the most important moments of my life and artisitic work. Mosaic art in the space of the new churches, on the wall of Maramures. Teamwork - transposition procedures and technical details to complete the artistic images from building of worship."Through the beauty and splendor of the unalterable material used, the mosaic was quite suitable to express the supernatural symbolism and translate figuratively spiritual values" (Al. Niccoli) The mosaic is the kind of art through which the brilliance of light and color brings us closer to the spirit and the invisible perfection".
\end{abstract}

Keywords: Fascination and mystery of Easter; The icon; Mosaic art; spiritual charge

Fascinația artei picturii, pe care încerc să o slujesc cum se cuvine, de câteva decenii bune este fără îndoială ,îndemnul" pe care 1-am primit din copilărie ,descoperind” icoana din casă cu candela niciodată stinsă sub ea și cu buchetul de busuioc, imagine la care de fiecare dată revin, ca la o stare primordială. Este de fapt punctul de pornire al meu pe un drum al artei, greu, sinuos, cu multe suișuri și coborâșuri, cu multe incertitudini și îndoieli, dar și bucurii nemărginite, atunci când te întâlnești cu împlinirea eforturilor și ostenelii în creația picturală. „Noi, fără ispită și încercare nu putem exista", ne spunea cu câțiva ani în urmă Starețul Mănăstirii Putna Arhimandritul Melchisedec, într-un dialog despre artă și creație.

\footnotetext{
* Prof. univ. dr., Facultatea de Litere, Universitatea Tehnică din Cluj-Napoca, str. Victoriei, nr.76, Baia Mare, (suciunicolae56@yahoo.com).
} 
Mai târziu, am descoperit uimit, catapeteasma bisericii din sat, cu toată rânduiala cerească, în scenele de pictură pe zid, în care culoarea, ritmul, linia, plasticitatea formelor, registrele compoziționale „exprimă adevăruri și slujesc realitatea comuniunii prin impărtășire dintre cele sau cei înfățișați în icoană și privitor."

Eruditul profesor Georgios Kordis, de la Facultatea de Teologie a Universității din Atena demonstrează ,ča există o cheie hermeneutică universală care deschide înțelegerea specifică spațiului ortodox în toate domeniile de exprimare a vieții oamenilor ca Biserică."

În anii 1994, pictând în biserică bolțile și pereții ( Biserica Apostolii Petru și Pavel din Smei județul Argeș) am realizat adevărul că icoana nu este o imagine statică, autonomă ci constituie o realitate în devenire, întregită în relația reală cu privitorul, ,...icoana este în fapt un eveniment sau închide în sine premisele devenirii întru eveniment, atunci când se realizează relația cu privitorul ei (...) funcția esențială a iconei nu este aceea de a da naștere la sentimente sau impresii estetice sau de altă natură, ci de a-l aduce în prezent pe cel înfățișat și de a-l pune în relație reală cu privitorul."

Privit retroactiv la temele creaţiei picturale ce s-au succedat de peste patru decenii, mă opresc la seriile de picturi realizate sub denumirea de Cer și Pământ. Aici, cerul, ca simbol universal ce exprimă credința, se identifică ca manifestare directă a transcendenței, a sacralităţii (ceea ce nici o ființă de pe pământ nu-l poate atinge) acest univers constituind o hierofanie inepuizabilă. „Prin urmare tot ce se petrece în spațiile siderale și în regiunile superioare ale atmosferei, revoluția iritmică a aștrilor, fuga norilor, furtunile, trăsnetul, meteorii, curcubeul - sunt momente ale acestei hierofanii."4

Pământul, simbolizând haosul primordial, substanța universală, materia primă despărțită de ape, devine în reprezentările picturale personale și Grădină a Raiului și vatră ancestrală a comunităților umane, vatră însemnând biserica, iar în jurul ei se rânduiesc toate celelalte case, ogoare, oameni, animale, grădini, livezi, ape , etc. Creațiile de pictură pe care le-am realizat în acestă serie tematică, de peisaje compoziţionale și buchete de flori tămăduitoare au constituit un material consistent pentru expoziția personală de pictură găzduită de Muzeul din Marseillas las Illas (Perpignon, Franța) din 2011.

\footnotetext{
${ }^{1}$ KORDIS, Georgios - Ritmul în pictura bizantină, Ed. Bizantină, 2008, p.9

${ }^{2}$ Ibidem

${ }^{3}$ Idem, p. 10

${ }^{4}$ CHEVALIER, Jean, GHEERBRANT Alain - Dicționarul de simboluri, Ed. Artemis, București, 1993, vol I, p.285
} 

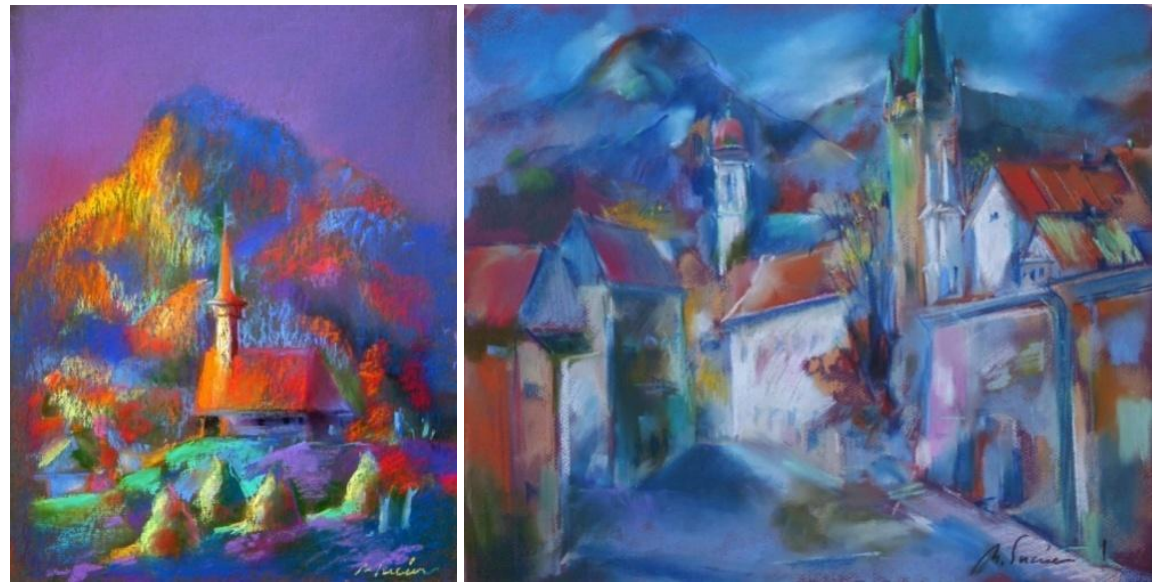

Nicolae Suciu - Biserica din deal Nicolae Suciu - Spre Centrul Vechi

O parte importantă din creațiile personale ale picturii de șevalet laice din totdeauna (încă din anii studenției) o constituie însuflețirea dată de izvoarele imaginare nesecate ale Sfintei Scripturi și ale programului iconografic din ortodoxie precum și din teologia icoanei: „Așadar, icoana este... o mărturisire a îndumnezeirii omului, a plenitudinii vieții duhovnicești, o comunicare prin imagine a ceea ce este omul în stare de rugăciune sfințită prin har. Intr-un anume fel, este o pictură „, după natură ”, dar după natura reînnoită. Ea este calea și mijlocul, este rugăciunea însăși. De aici, măreția icoanei, simplitatea ei, calmul mișcării, ritmul liniilor și al culorilor sale, care decurg dintr-o armonie interioară desăvârşită nu rezultă câtuşi de puțin, că doar sfinții pot face icoane." Am avut aplecarea și preocuparea și am stăruit asupra reprezentării Chipului Mântuitorului $n$ cosmosul iconografic, din Istoria Artelor, secole la rândul, oscilând între două înfățișări ale Domnului inspirate din Vechiul Testament, văzând astfel în Hristos-omul cu chipul ,dezgustător" și plin de răni, pe Hristos jertfa, iar în Hristos-Dumnezeu, cu chip frumos și slăvit, pe Hristos Jertfitorul, El fiind „Cel care jertfește și cel ce se jertfește.” Din această serie de creații fac parte lucrări de pictură „Crist”, „Răstignirea la marginea drumului”, „,Troița”, în care reistrul cromatic încărcat de dramatism, subliniază și pune în valoare Chipul Mântuitorului. Uneori corpul nu are brațe (semn al delăsării oamenilor, al ,însemnelor" timpului), dar pentru pictor mesajul de verticalitate, constituie un puternic simbol al spiritualităţii, al ascensiunii.

${ }^{5}$ USPENSKY, Leonid - Teologia icoanei, Ed. Renașterea Patmos, Cluj-Napoca, 2012, p.10

${ }^{6}$ Arhm. BOCHIU, Sofian - Chipul Mântuitorului în iconografie, Ed. Bizantină, București, 2001, p.14 


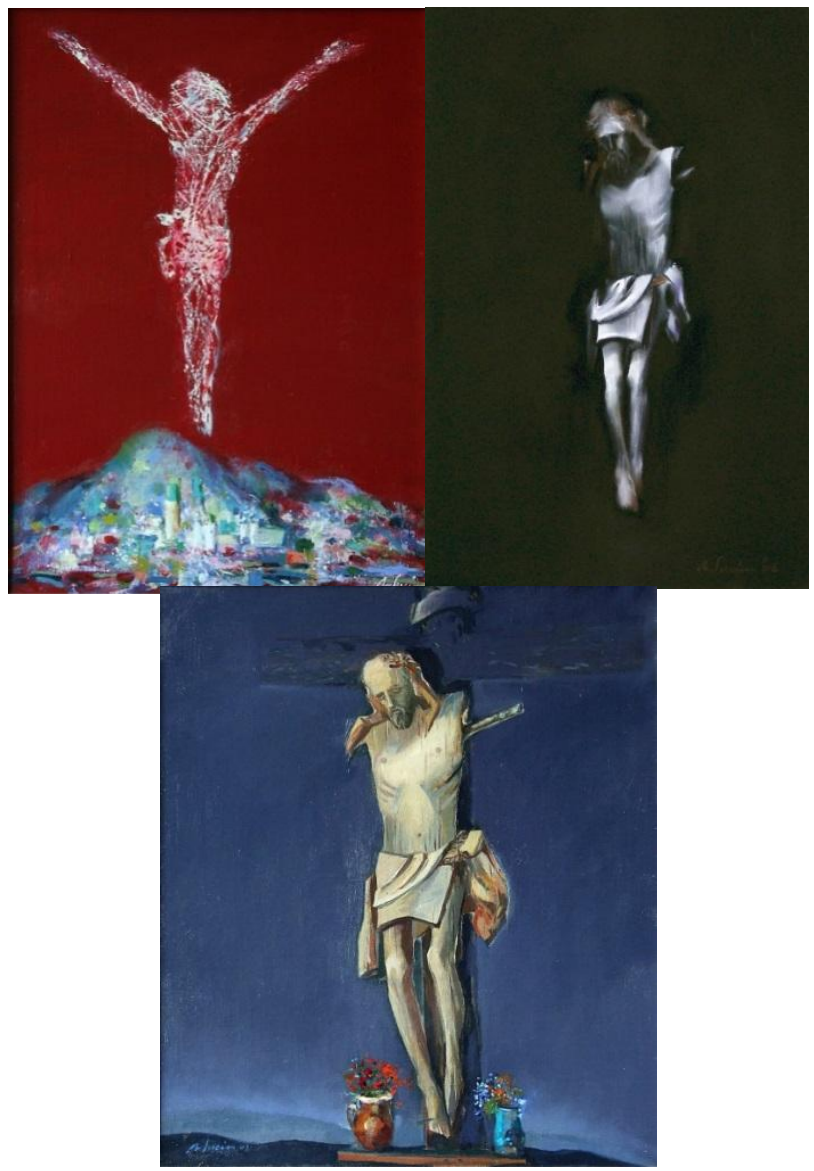

Nicolae Suciu - Răstigniri (I,II,III)

Achiropitele - chipurile nefăcute de mână „care s-au bucurat de multă cinstire în înteaga lume creștină din Orient și Occident se pot rezuma la cele două prototipuri: „Fața bizantină”, orientală, pe mahrama trimisă lui Abgar și „Fața romană”, occidentală, chipul Hristosului Suferind pe mahrama Veronicăi."

\footnotetext{
${ }^{7}$ Ibidem, p.27
} 


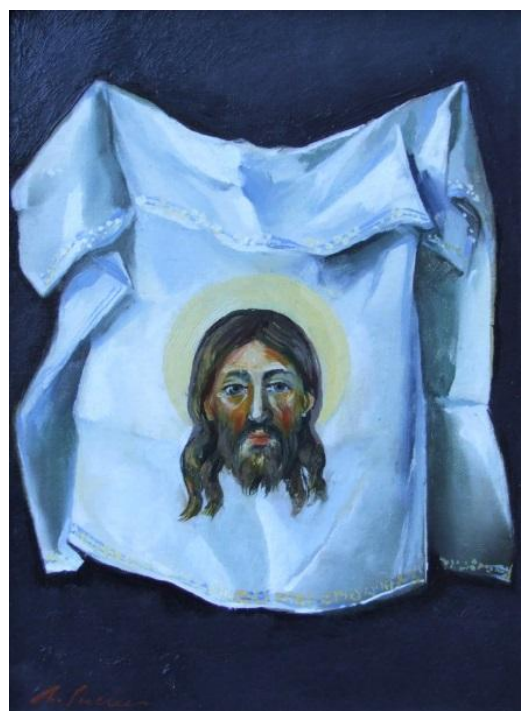

Nicolae Suciu - Năframa Sfintei Veronic

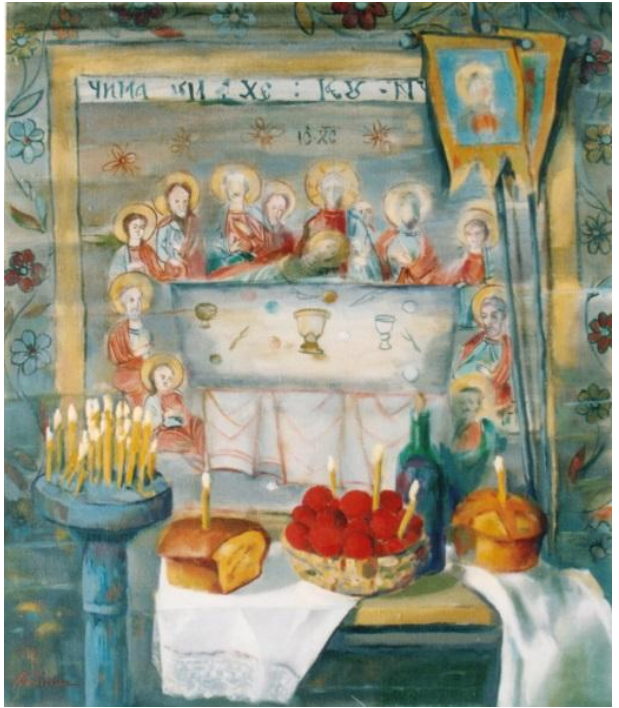

Nicolae Suciu - Noapte de Inviere

Sunt teme majore în propria-mi creație, cât și exemple de referință, pentru posibilitățile de realizare ale tematicilor și metodelor de lucru ale studenților specializării Arte Plastice - Pictură pe care-i coordonez Năframa Sfintei Veronica, Taina Sfintei Lumini, cu Nopti de Inviere au fost reperul spiritual pentru realizarea picturii „Noapte de Inviere”, fundalul picturii ce reprezintă Cina cea de Taină, din Biserica Sf. Mihail din Rogoz, Maramureș, iar în fața ei lângă sfeșnicul cu lumânări aprinse, sunt aduse păștile pentru sfințire (imagine inspirată din copilărie, din biserica din sat, Sf. Dumitru din Sărbi, Vaslui). Albul imaculat al ştergarului, pasca cu însemnul crucii, vinul roșu pentru împărtășanie, precum și ouăle înroșite, stabilesc armonii cromatice pline de înțelesuri și har, ce întregesc bucuria lăuntrică a miracolului Învierii. În munca didactică cu studenții , în cadrul orelor de Tehnici alternative picturii de șevalet și a orelor de Tehnicile plastice și artelor decorative, stabilesc teme iconografice cum ar fi: pictura pe sticlă - icoană populară după izvoadele din Transilvania (la anul I), iar la anul II - pictura pe lemn - icoan bizantină, după icoane din arta medievală românească, arta bizantină, arta rusă, iar la anul III - tehnica mozaicului (mozaicul în casetă cu reprezentări de icoane bizantine, motive decorative florale, cadraje ornamentale). Un lucru îmbucurător îl constituie abordarea tehnicii „picturii” în mozaic, această - ,pictură pentru eternitate”, la bisericile de zid din Maramureș și nu numai. O reprezentare monumentală a hramului bisericii Sfântul Ilie din Baia Mare este un medalion cu diametrul de 3,5 m, realizat în tehnica mozaicului policrom, îl reprezintă pe Proroocul Ilie în gura peșterii, hrănit de corb, conform perceptelor din Erminie. 



Etape de lucru în atelier - Mozaicul de la Biserica Sf. Ilie Baia Mare

Chipul elaborat prin axe compoziționale curbe, alternând cu ordonarea ritmică a liniilor oblice, de pe veșminte, racordate la planurile succesive de reprezentare a stâncilor susținute de dialogul lumină-umbră, conferă dinamism compoziţiei încadrate în cerc.

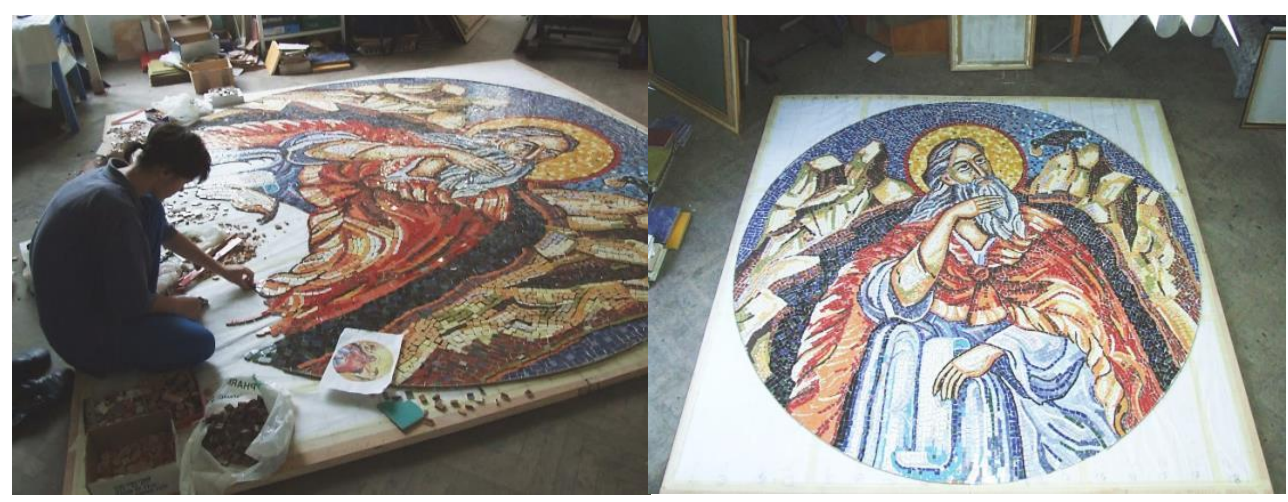

Etape de lucru în atelier - Mozaicul de la Biserica Sf. Ilie Baia Mare 


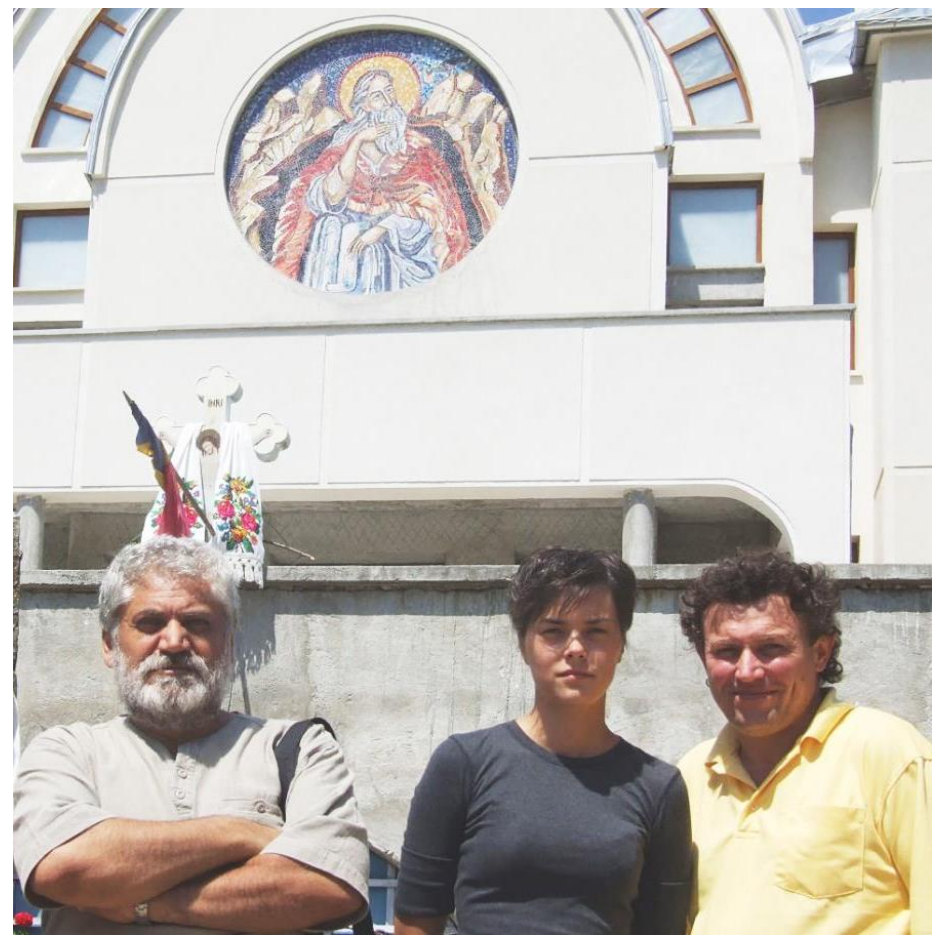

Nicolae Suciu și colaboratorii studenți Csurka Imola, Ioan Pop

Trebuie menționat, aici, că acest efort creator având ca tematică universul iconografic, s-a concretizat într-o amplă expoziţie la Muzeul de Artă, Centrul Artistic Baia Mare - cu titlul "Icoana - Puterea tradiției", ce au reunit munca câtorva generații de studenți ai secției de artă din centrul Universitar Nord din Baia Mare. Au avut totodată înțelegerea și deschiderea de a aduce puterea binefăcătoare a icoanei într-un spațiu pentru oamenii privați de libertate. Proiectul realizat împeună cu asistenta Greti-Adriene Papiu și a unei grupe de studenți, a iconostasului bisericii Sfântul Gheorghe, a Penitenciarului Baia Mare, a constituit pentru mulți absolvenți piatra de încercare, astfel că azi reușesc să-și câștige existența din pictarea icoanelor (sticlă, lemn, mozaic) restaurări și pictări de biserici, contribuind la continuitatea și statornicia acestor tradiții în spațiul românesc.

Icoana, în lumea de azi, din punct de vedere spiritual dar și artistic, constituie un fenomen semnificativ. „Tocmai această perioadă furtunoasă este ceea care își face apariția în icoana ca un tezaur suprem al artei omenești. Într-adevăr dacă decadența spirituală se manifestă prin uitarea icoanei, trezirea spirituală provocată de catastrofe și de convulsii ne conduce înspre icoană, ne incită să-i înțelegem sensul, să luăm act de ea. Ea nu mai apare ca ținând de trecut, ea renaște ca prezentul nostru. Ca să o caracterizăm, găsim expresii noi. O înțelegere lentă a sensului duhovnicesc al icoanei vechi tocmai începe; descoperim în ea un spirit infinit mai înalt 
decât al nostru, decât roadele civilizației noastre. Ea nu mai reprezintă doar o valoare artistică sau culturală, ea este o relevare a experienței duhovnicești ortodoxe, prin mijlocirea artei, o „teologie în imagini” care s-a manifestat în trecut, în perioade de mari necazuri și catastrofe. Și tocmai în vreme de necaz intrevedem sensul catastrofelor contemporane în lumina forțelor spirituale ale icoanei." 8

Întruchiparea celor susținute anterior de Leonid Uspensky, îl constuie, un eveniment deosebit de important, ce nu a fost mediatizat la noi, cu excepția unei prelegeri publice în cadrul unei expoziţii la Baia Mare, curatoriate de subsemnatul, 1-a care 1-am avut invitat pe cel ce a gândit acest complex demers artistic. Este vorba de pictorul Pierre Tchakhotine, cu dublă cetățenie franceză și rusă care are rezidența în Italia. Facem parte și suntem membrii ai Asociaţiei Pictorilor Pasteliști din Polonia, unde de altfel ne-am și întâlnit în anul 2006 și pe care 1-am invitat într-o rezidență artistică la Baia Mare. Proiectul „L'Arte per la pace in Europa e nel mondo”, la care am participat ca invitat propunea icoana Sfintei Anastasia din Sirmio (281304) - o speranță pentru pace - ce s-a concretizat într-o manifestare artistică europeană, susținută de UNESCO, Consiliul Europei, conduceri din marile orașe Iaroslavi (Rusia), Mitroviza (Serbia), Zadar (Croația), Mondovi (Italia), precum și de numeroși prelați ai bisericii, personalități ale culturii, artei și politicieni, în septembrie - octombrie 2007 și care a reunit creația a 220 de artiști proveniți din 17 țări europene, cu 280 de opere selecționate.
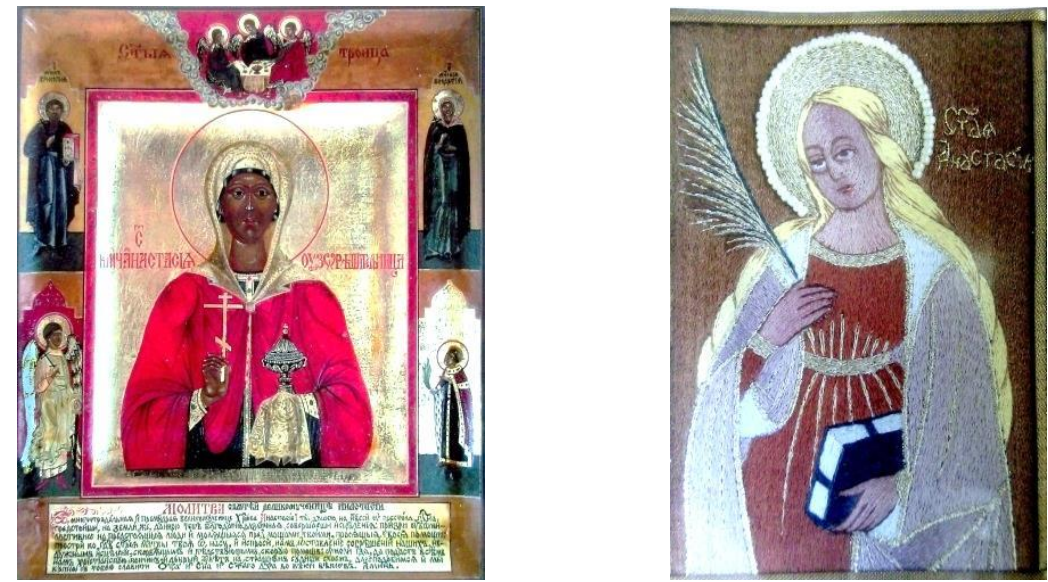

Gaverdovski Nikolaj - Icoana Sf. Anastasia Lavrova Nadia - Icoana Sf.Anastasia

În faţa atrocităţilor comise de beligeranții războiului iugoslav, este aleasă icoanaSfintei Anastasia din Sirmio, din provincia Illiria, ca simbol al martirajului acesteia după 1700 de ani, ca apărătoarea prizonierilor de război, celor privați de libertate din convingeri religioase și politice, a celor

${ }^{8}$ USPENSKY, Leonid - Teologia icoanei, Ed. Renașterea Patmos, Cluj-Napoca, 2012, p.462 
prigoniţi în închisori. Mesajul transmis în creaţia artistică a artiștilor participanți la aceste evenimente artistice, au avut în centrul atenției reprezentarea iconică a Sfintei Anastasia, ca martiră a creștinătăţii, precum și scene și acțiuni de binefacere în rândul năpăstuiților sorții, realizate în diferite tehnici ale picturii, graficii, sculpturii.
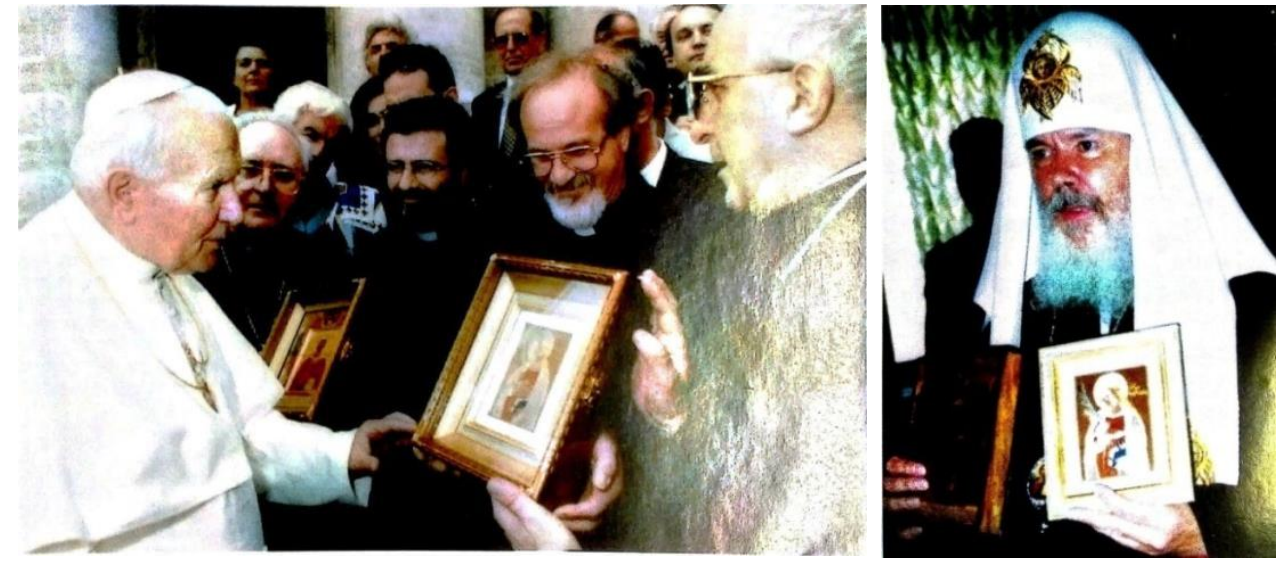

Binecuvântarea Icoanelor de către Sanctitatea sa Papa Ioan Paul al III-lea (1997) și Patriarhului Moscovei Alexei al II-lea

În pregătirea acestui eveniment realizatorul acestui proiect a ales icoana artistei ruse Nadia Lavrova - „Sfânta Anastasia" - lucrată ca broderie în fir de aur, argint și mătase după fresca de la 1493 din Biseria San Giovanni, Roma, precum și Icoana Sfintei Anastasia, pictată în tempera pe lemn și foiță de aur a pictorului Nicolai Gaverdovski. Aceste două icoane au primit binecuvântarea Sanctității sale Papa Ioan Paul al III-lea (1997) a Patriarhului Pavel al Serbiei (2004), al Patriarhului Moscovei Alexei al IIlea și au fost duse, la cosmodromul de la Baikoneur, pentru a ajunge pe Stația orbitală MIR - de către astronauții Anatoli Soloviev și Nicolai Budarin. Gândul realizatorului de proiect s-a împlinit, cele două icoane au ajuns în spațiu și-au săvârșit trei mii de rotații în jurul Pământului, însumând 1.500.000 km - distanța estimată de la Pământ la Soare.

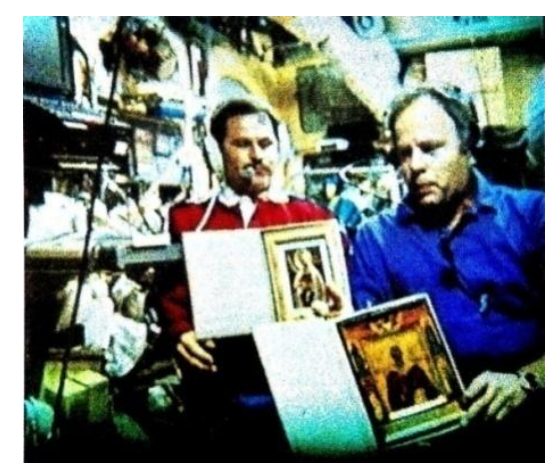

Icoanele în mâinile astronauților Anatoli Soloviev şi Nicolai Budarin 
Efortul creator al artiștilor, alături de înalți prelați ai bisericii creștine Catolice și Ortodoxe la care s-au adăugat foruri politice, culturale, științifice, de primă mână, prin etape succesive au realizat prin omogenizarea icoanei Sfintei Anastasia o punte de legătură a creștinătății între Orient și Occident, creare de raporturi de fraternitate între popoarele Europei, precum și a întregii lumi, pentru stabilirea păcii. Alegerea simbolică a icoanei Sfintei Anastasia, ca solie de pace și opririi învrăjbirii între oameni, conferă prin puterea exemplului, dimensiunea spirituală determinantă în actul creației, de puterea miraculoasă și vindecătoare.

\section{Bibliografie:}

KORDIS, Georgios - Ritmul în pictura bizantină, Ed. Bizantină, 2008.

USPENSKY, Leonid - Teologia icoanei, Ed. Renașterea Patmos, Cluj-Napoca, 2012.

CHEVALIER, Jean, GHEERBRANT Alain - Dicționarul de simboluri,Ed. Artemis, București, 1993 vol I.

Arhm. BOCHIU, Sofian - Chipul Mântuitorului în iconografie, Ed. Bizantină, București, 2001. 